\title{
IDENTIFIKASI PENDEKATAN WHITE CUBE DAN REGIONALISME KRITIS PADA ARSITEKTUR GALERI SENI DI YOGYAKARTA
}

\author{
Marchelia Gupita Sari \\ Universitas Pradita \\ marchelia.gupita@pradita.ac.id \\ Imaniar Sofia Asharhani \\ Universitas Pradita \\ imaniar.sofia@pradita.ac.id
}

Naskah diajukan pada: 28 Februari 2020

Naskah revisi akhir diterima pada: 17 September 2020

\begin{abstract}
Abstrak
Regionalisme dalam arsitektur kerap dibahas sebagai respon terhadap arsitektur modern yang bersifat univalen dan melunturkan nilai-nilai kesetempatan. Estetika galeri seni dengan pendekatan white cube yang berakar pada modernisme telah mengglobal atau melanda dunia, seperti halnya international style dalam arsitektur. Yogyakarta kini tengah menghadapi isu lokalitas dalam arsitektur yang dapat mencerminkan identitasnya sebagai kota seni dan budaya. Galeri seni memiliki peranan penting untuk menyebarkan kesenian kontemporer yang dinamis. Penelitian ini bertujuan untuk mengidentifikasi penerapan pendekatan white cube pada arsitektur galeri seni dan penerapan regionalisme kritis sebagai respon terhadap modernitas. Penelitian ini menggunakan metode penelitian deskriptif kualitatif. Analisis data dilakukan dengan komparasi antarkasus berdasarkan indikator dari regionalisme kritis dalam arsitektur. Penarikan kesimpulan berdasarkan kecenderungan penerapan white cube dengan indikator regionalisme pada kasus. Hasil penelitian menunjukkan bahwa pendekatan regionalisme ditemukan pada kasus yang menekankan tektonika, respon terhadap iklim, dan respon terhadap konteks sekitar. Karya seni di galeri seni Yogyakarta ternyata tidak serta merta dibebaskan dari konteks sekitar seperti halnya konsep white cube gallery.
\end{abstract}

Kata-kata Kunci: Arsitektur, Galeri Seni, Regionalisme Kritis, White Cube

\section{IDENTIFICATION OF WHITE CUBE APPROACH AND REGIONALISM IN ART GALLERY ARCHITECTURE IN YOGYAKARTA}

\begin{abstract}
Regionalism in architecture is often discussed as a response to modern architecture, which contains a univalent value and attenuates the values of context. The aesthetics of art galleries with the concept of white cube rooted in modernism have become trend in the world and international style in architecture. Yogyakarta is currently facing locality in architecture that can reflect its identity as a city of arts and culture. Art galleries have an essential role in spreading dynamic contemporary art. This study aims to identify the white cube approach to art gallery architecture and critical regionalism to respond to modernity. This research uses descriptive qualitative research
\end{abstract}


methods. Data analysis was conducted by comparisons between cases based on indicators of crucial regionalism in architecture. The conclusion is based on the tendency of applying white cube with indicators of regionalism in cases. The results showed that the regionalism approach was found in cases that emphasized tectonic aspects, responses to climate, and responses to the surrounding context. Artwork in the Yogyakarta art gallery is not necessarily freed from the surrounding context, such as the concept of the white cube gallery.

Keywords: Architecture, Art Gallery, Critical Regionalism, White Cube

\section{Pendahuluan}

Pada laman Yogyakarta Contemporary Art Map (2020) setidaknya tercatat tebaran 50 (lima puluh) ruang seni dan galeri seni di kota Yogyakarta dan bagian selatan kota. Keberadaan galerigaleri seni dinilai penting sebagai penunjang identitas Yogyakarta sebagai kota seni dan budaya. Iklim hangat berkesenian seakan meneguhkan Yogyakarta sebagai kota untuk orang-orang kreatif melalui event-event berskala lokal hingga internasional. Galeri seni selain menjadi wadah eksperimen, wadah penyampaian pesan lewat publikasi karya, kerja kolektif para artist atau para seniman, juga dipandang sebagai tempat bagi pengunjung yang ingin mengapresiasi karya seni, diskusi, bahkan mengisi konten media sosial.

Menjamurnya galeri seni ditengarai oleh sekolah seni Institut Seni Indonesia (ISI) pada selatan Yogyakarta pada tahun 1980-an. Menilik Swastika (Sari, 2019) menulis bahwa pendekatan desain arsitektur pada galeri seni ternyata beragam. Mulai dari bangunan galeri seni yang bernuansa minimalis maupun industrialis yang 'kontras' dengan lanskap permukiman, maupun bangunan yang mencoba untuk 'selaras' dengan kondisi lingkungan di sekitarnya. Galeri seni sering dikembangkan dengan pendekatan terhadap pengalaman ruang para pengunjung dan berfokus pada interiornya. Oleh karena itu, pembahasan mengenai arsitektur galeri seni menjadi hal yang menarik mengingat potensi peningkatan kuantitas galeri seni kota Yogyakarta nantinya. (Bruhn, 2013) menyoroti kian menjamurnya alternative art space sebagai altenatif galeri seni.

Perlu untuk diperhatikan bagaimana bangunan galeri seni dapat sejalan dengan perkembangan jaman, namun tidak melupakan lokalitas. Globalisasi yang bersifat universal telah membawa homogenitas pada karya arsitektur. Suha Ozkan (Moore, 2007) memaparkan bahwa modernisme melalui internasionalisme begitu mengagungkan nilai universal yang dapat diaplikasikan di mana saja. Hal ini telah berpuluh-puluh tahun menguasai sekolah arsitektur, industri bangunan, bahkan muncul menjadi ideologi. Paham modernisme dalam arsitektur kental dengan frase tabula rasa, yaitu seperti meletakkan bangunan di lahan kosong tanpa konteks tapak yang kuat. Oleh karena itu, rekayasa tapak kerap dilakukan sedemikian rupa tanpa menghiraukan konteks tapak. Dari segi lokasi, desain bangunan yang sadar dengan wilayah keberadaannya semestinya akan lebih menghargai topografi dan konteks lokasi eksisting.

Akademisi yang membahas pendekatan white cube adalah Brian O'Doherty dalam publikasinya yang berjudul Inside White Cube Gallery (O’Doherty, 2000). Pendekatan White Cube Gallery sebenarnya telah dimulai abad 19, di mana karya seni diisolasi dari konteks untuk menghindari overcrowding dan memberi penekanan pada kualitas karya seni ketika dipamerkan. Sebagai contoh, National Gallery di London menerapkan peletakan karya seni pada level mata manusia secara sebaris dengan penataan yang teratur sehingga pengunjung tidak harus mendongak atau bergerak ekstra untuk dapat menikmati karya tersebut. Oleh karena itu, dinding galeri seni terlihat lebih kosong karena penempatan tersebut. Karya seni kontemporer dipamerkan di konteks yang berbeda dan bagaimana konteks tersebut dapat mempengaruhi karya seni. Pendapat bahwa ruang pada galeri seni menjadi ruang yang 'higienis' seperti laboratorium percobaan yang lepas dari konteks, dan 
O'Doherty membandingkan bagaimana gereja dengan ruang sakralnya akan seperti halnya karya seni menjadi fokus utama.

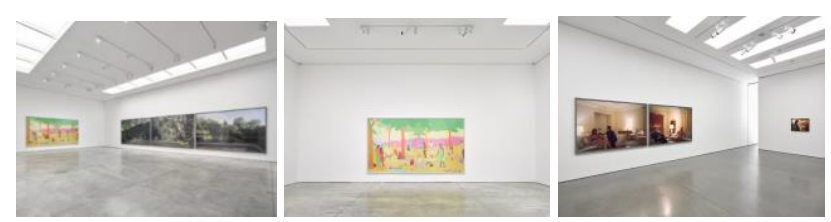

Gambar 1. Estetika White Cube Gallery

Sumber: https://whitecube.com/exhibitions/exhibition/jeff_wall_masons_yards_2019, diakses pada 10 September 2020

\section{White Cube Gallery Dalam Pembahasan Regionalisme Kritis Dalam Arsitektur: 'Placelessness' Versus 'Place'}

Artikel Towards a Critical Regionalism: Six Points of an Architecture Resistance membahas tentang regionalisme kritis (Frampton, 1983). Topografi, konteks, iklim,cahaya, bentuk tektonik,dan taktilitas menjadi hal penting dalam menyelaraskan bangunan terhadap setempat. Pendekatan ini mengasumsikan bahwa bentuk-bentuk tertentu menyandang peran untuk menampilakan ciri daerah tertentu (Hidayatun, Prijotomo, \& Rachmawati, 2013). Namun begitu, Kesetempatan dapat nampak tanpa harus selalu menampilkan bentuk-bentuk masa lalu secara vulgar. Tidak seperti vernakularisme, modern regionalism dibagi menjadi dua, yaitu concrete modern regionalism dan abstract modern regionalism. Concrete regionalism mengakomodasi seluruh pendekatan untuk abstraksikan elemen bentuk dari masa lalu, sedangkan Abstract Regionalism lebih memperlihatkan kualitas abstrak dari suatu bangunan, misalnya; massing, solids and void, proportions, sense of space, use of light, dan structural principle pada bentuk yang merupakan hasil reinterpretasi.

Berkaitan dengan galeri seni, Kenneth Frampton juga telah membahas bagaimana interior galeri seni menjadi placeless disebabkan oleh praktek kurasi modern memiliki preferensi pencahayaan buatan di ruang galeri-galeri seni. Hal ini membuat galeri seni memiliki nuansa yang seragam di berbagai tempat dengan teknik-teknik pencahayaan universal. Asalkan galeri seni menjadi terang dibuat dengan cermat, maka efek sinar matahari yang dianggap merugikan dapat dihindari. Jika ditinjau lebih jauh, nuansa pencahayaan alami pada pameran akan berubah sesuai waktu, musim, kelembaban, dan sebagainya. Selain itu, terdapat penggunaan pendingin udara di manapun dewasa ini telah mengalahkan penghawaan alami padahal ia meyakini bahwa penghawaan alami merupakan salah satu cerminan kontrol iklim dari lokasi. Kejelasan bagaimana beban-beban dapat disalurkan bangunan tidak dapat terlihat jika struktur dan konstruksi ditutup atau disembunyikan. Tektonika tidak hanya sekadar mengekspos struktur dan konstruksi, namun permainan material, craftwork, dan gravitasi yang terwujud dalam keseluruhan struktur bangunan. Terlebih bagaimana tektonika yang berasal dari barat dapat mendasarkan diri dari lokalitas tempat bangunan tersebut berada (Rembulan, 2014).

Lebih jauh tentang fenomena galeri seni yang placeless, dewasa ini konsep white cube pada galeri seni masih tumbuh dalam praksis pameran seni kontemporer secara global. Kemunculan pendekatan white cube merupakan paham modernisme dikembangkan untuk ruang galeri yang menganut placelessness atau bersifat netral. Oleh karena itu, galeri berkonsep white cube diterima sebagai tempat yang lepas dari konteks, di mana waktu dan ruang sosial dikesampingkan agar pengunjung dapat memahami karya seni yang dipamerkan. Dilansir dari laman https://www.tate.org.uk/art/art-terms/w/white-cube, konsep white cube pada galeri seni merespon abstraksi karya seni modern, dan menekankan aspek warna netral dan tata cahaya buatan, misalnya pada De Stijl maupun Bauhaus. Pembahasan tentang ruang seni kontemporer white cube secara umum sudah dilakukan oleh (Evon, 2017) namun belum terdapat bagaimana galeri seni secara 
khususnya memakai pendekatan white cube yang bersifat placeless, namun tetap memperhatikan lokalitas.

Dari tinjauan pustaka, didapatkan bahwa pada galeri seni dengan pendekatan white cube kurang didapatkan adanya hubungan visual antara interior dengan eksterior. Interior menjadi sesuatu yang terpisah karena cenderung untuk mengisolasi diri dari lingkungan luar karena interior galeri seni tidak mau 'terkontaminasi' oleh ruang luar. Padahal, di dalam arsitektur bangunan dengan pendekatan regionalisme kritis diharapkan mampu berdialog dengan kawasan. White Cube identik dengan placelessness, sesuatu yang ditentang oleh Regionalisme yang mengedepankan place. Universalitas atau ruang generik white cube yang dapat diproduksi di manapun bergesekan dengan adanya kekhususan dari area setempat yang dimunculkan pada ekspresi arsitektural. Taktilitas yang dibawa oleh regionalisme berlawanan dengan galeri seni yang steril. Walaupun begitu, dari segi bentuk, regionalisme kritis tidak lantas harus memunculkan ekspresi vernakular karena arsitektur dengan pendekatan regionalisme kritis mengikuti kebaikan yang ditawarkan arsitektur modern dan mengikuti perkembangan jaman.

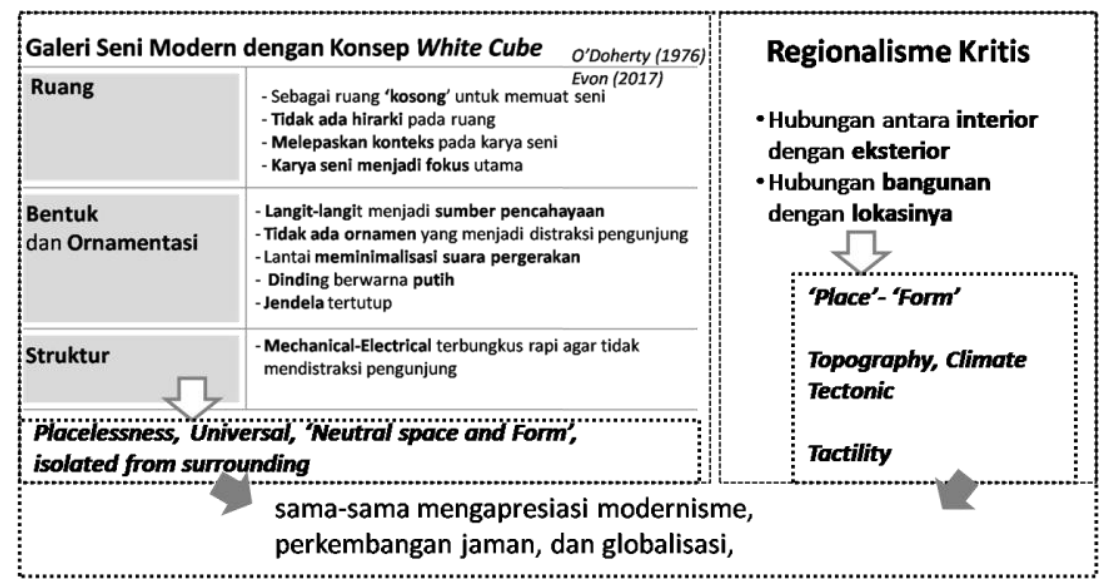

Gambar 2. Ringkasan Hubungan Galeri Seni Pendekatan White Cube dengan Regionalisme Kritis Sumber: Analisis Penulis, 2019

\section{Art Space dengan Pendekatan Regionalisme}

Karya Louis Kahn Kimbell Art Museum dibahas oleh Canizaro dalam sekumpulan essay (Moore, 2007) sebagai museum yang merespon kesetempatan, yaitu daerah Fort Worth yang identik dengan horizontalitas sehingga hal itu menjadi inspirasi massa bangunan. Kahn tidak hanya membenamkan bentuk secara eklektik dari sepanjang jalan kota Texas, namun Kahn menampilkan nuansa Texas dari segi warna, tekstur, dan cahaya. Warna abu-abu dan cokelat kecoklatan bangunan seperti warna lanskap asli dengan rumput kering dan substrat batu kapur. Karakter taktil dari material bangunan ditekankan untuk merespon matahari Texas. Cahaya dan bayangan dimodulasi dengan kemahiran dan pemahaman desain. Desain Kimbell Art Museum menunjukkan bagaimana pencahayaan alami dimungkinkan dipakai tanpa membahayakan karya seni. Selain itu, terdapat hubungan secara visual antara eksterior dan interior bangunan. 


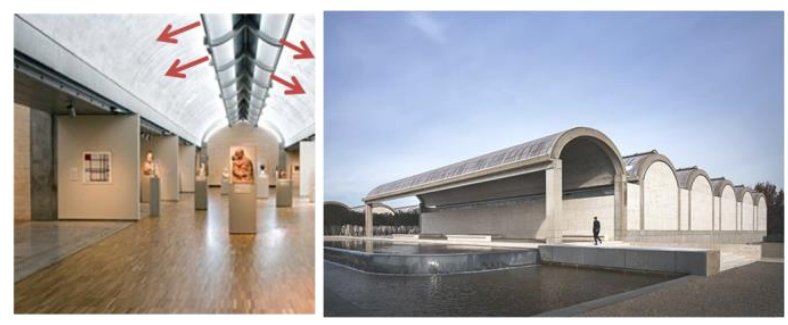

Gambar 3. Kimbell Art Museum

Sumber: www.kimbellart.org diolah oleh penulis, diakses pada 1 September 2019

Setelah melakukan tinjauan pustaka, dengan konteks kota Yogyakarta yang kerap disebut sebagai kota seni dan budaya di tengah galeri seni, maka tujuan tulisan ini adalah:

1. Mengidentifikasi penerapan pendekatan white cube yang umumnya menjadi ciri khas galeri seni di dunia yang kerap disebut melepaskan diri dari konteks ruang sekitar pada galeri seni di kota Yogyakarta

2. Mengidentifikasi seperti apa indikasi prinsip regionalisme yang dapat tercermin dari bangunan galeri seni di Yogyakarta

\section{Metode}

Penelitian ini bersifat deskriptif kualitatif dengan paradigma rasionalistik. Penelitian ini memiliki beberapa tahapan, yaitu studi literatur mengenai regionalisme, survei lapangan, analisis data dengan teknik komparasi antarkasus, dan proses sintesis untuk penarikan kesimpulan. Penentuan objek penelitian berdasarkan kriteria: 1) lokasi bangunan galeri seni berada di lingkup Kawasan Perkotaan Yogyakarta (KPY) termasuk di dalamnya bagian selatan kota Yogyakarta yang masuk dalam RIKBPY (Rancangan Induk Kota Budaya Perkotaan Yogyakarta 2014-2034), 2) tahun pembangunan atau telah mengalami perbaikan (renovasi) pada rentang tahun 2000 sampai dengan 2020 atau kurang lebih 2 (dua) dekade, 3) telah memiliki ulasan tentang elemen arsitektural atau unsur lokal kedaerahan di media sosial, berita cetak, website, maupun dari narasi sang arsitek sendiri. Tidak ada batas antara istilah art space dengan galeri seni karena data tentang galeri bersumber dari http://artmapjogja.com/ruang-seni/ dan Dinas Kebudayaan Daerah Istimewa Yogyakarta. Objek penelitian adalah galeri seni komersial, maupun ruang-ruang para seniman untuk berkolaborasi.
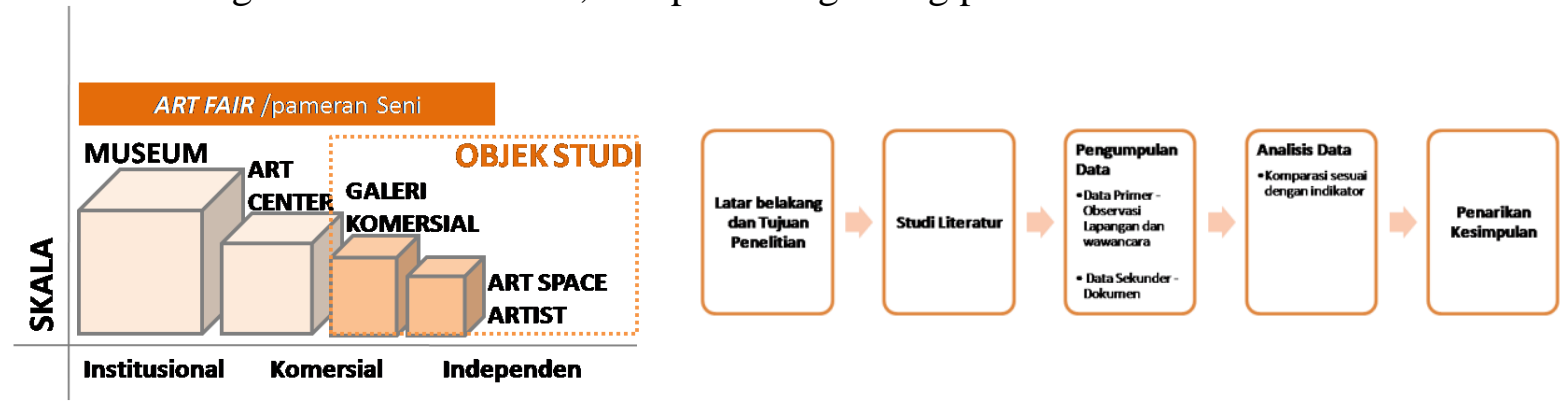

Gambar 4. Lingkup Objek Penelitian Dan Alur Penelitian

Sumber: Penulis, 2019)

Teknik pengumpulan data dilakukan melalui observasi lapangan, wawancara dengan petugas atau pengurus galeri seni, didukung dengan studi literatur. Data primer yang didapatkan berupa foto, sketsa, dan catatan. Data sekunder adalah data pendukung, yaitu foto, video, ulasan bangunan yang berasal dari media sosial, media cetak, maupun laman website resmi galeri seni. Analisis data dilakukan dengan sketsa-sketsa skematik mengenai aspek arsitektural bangunan yang mengindikasikan adanya pendekatan white cube berdasarkan (Evon, 2017) dan maupun pendekatan regionalisme kritis. Tinjauan tentang melihat karya arsitektur dikelompokkan berdasarkan indikator dari regionalisme kritis (Frampton, 1983) sebagai acuan utama. Dari hasil olahan data, didapatkan 
kesimpulan apakah bangunan galeri seni di Yogyakarta menerapkan white cube dan ulasan indikasi penerapan regionalisme dalam kasus terpilih.

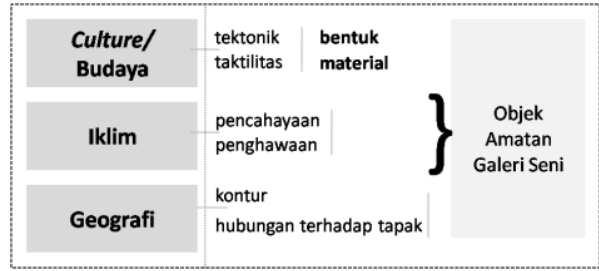

Gambar 5. Penyusunan Indikator Regionalisme Kritis

Sumber: Ozkan dalam Canizaro, 2007; Frampton, 1983; diolah penulis, 2019

Indikator penelitian dijelaskan sebagai berikut, culture atau budaya membawa pemahaman tektonika, yaitu melihat teknik menyelesaikan bentuk bangunan dan komponen struktur-konstruksi secara estetis, serta tetap mendukung bangunan galeri seni. Taktilitas membahas elemen arsitektural yang mampu membangkitkan sensori manusia. Pada bagian iklim, melihat seberapa jauh galeri seni berusaha responsif terhadap iklim melalui pencahayaan dan penghawaan alami. Pada segi geografi, topografi akan membahas masa bangunan dengan topografinya, maupun terhadap lingkungan sekitar. Setelah melakukan seleksi terhadap objek studi, didapatkan kasus sebagai berikut; 1) Kedai Kebun Forum (KKF), 2) Via Via (VV), 3) Galeri Lorong (GL), 4) Sangkring Art Space (SAS), 5) Sarang Building Art Space (SBAS), 6) Langgeng Art Foundation (LAF), 7) Pendhapa Art Space (PAS), dan Rumah Seni Cemeti (RSC). Kedelapan kasus ini merupakan bangunan dengan fungsi galeri seni yang memuat kegiatan pameran seni, pertunjukan seni, residensi seniman, maupun diskusi publik. Dua di antaranya merupakan galeri seni dengan fungsi lain berupa restoran atau kafe.

\section{Hasil dan Pembahasan Bentuk}

Dari hasil analisis didapatkan 5 (lima) pada 9 (sembilan) kasus terpilih yang menunjukkan ketiadaan penggunaan bentuk maupun ornamentasi yang memiliki unsur kedaerahan secara vulgar, melainkan fasad dengan geometri dasar. KKF memiliki bentuk yang sangat geometris karena berdasarkan wawancara dengan pemilik, KKF menggunakan konsep 'industrial' yang mengedepankan efisiensi dan efektivitas dalam pembangunan dan fungsinya. LAF memiliki bentuk persegi panjang polos tanpa warna yang mencolok, sedangkan SBAS juga menggunakan geometri dasar kubus.

Pendekatan berbeda terhadap bentuk bangunan dilakukan pada PAS, RSC, dan GL di mana bentuk bangunan menunjukkan adaya reinterpretasi terhadap arsitektur masa lalu atau bangunan lama melalui bentuk atap. PAS, GL, dan RSC memiliki kemiripan terhadap atap limasan dan joglo, rumah tradisional Yogyakarta. Namun begitu, pada RSC dan SBAS bentuk yang menujukkan interpretasi terhadap arsitektur masa lalu ternyata disandingkan dengan bentuk massa bangunan lain yang sangat geometris. Tidak ada kasus yang hanya menampilkan satu inspirasi bentuk-bentuk vernakular, selalu ada kecenderungan untuk bentuk massa bangunan geometris dasar yang menyertainya. 


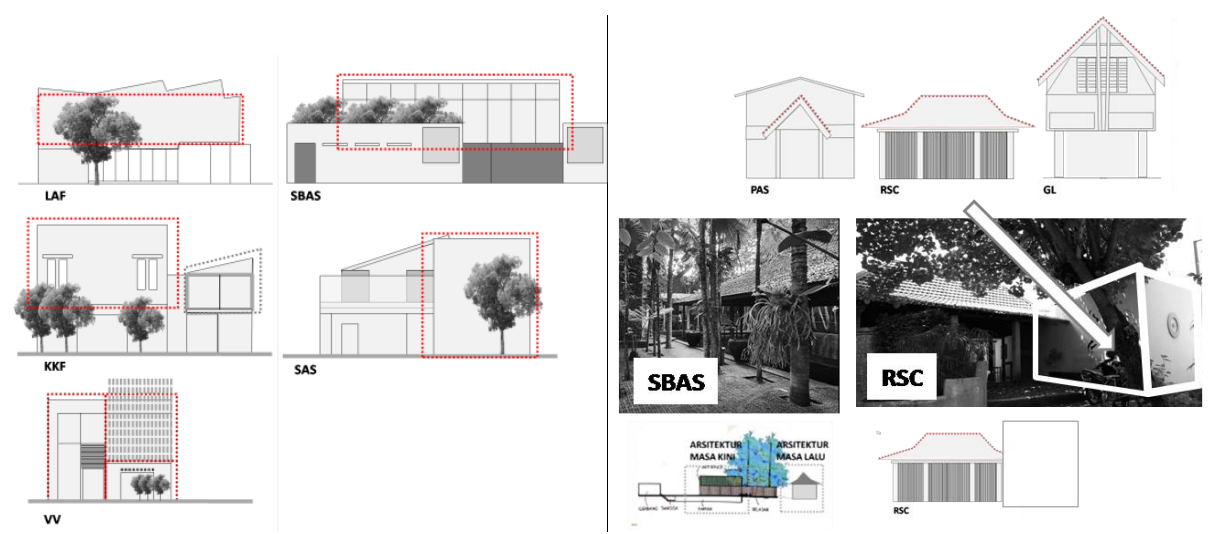

Gambar 6. Bentuk Galeri Seni dengan Geometri Dasar Dan Galeri Menunjukkan Reinterpretasi Atas Bangunan Vernakular Sumber: Olahan Penulis, 2019

\section{Tektonika}

Pendekatan regionalisme kritis pada arsitektur lebih mementingkan teknik-teknik membangun yang bernilai estetis ketimbang tampilan bentuk semata. Pada kasus GL,PAS,RSC,SBAS, ditemukan reinterpretasi detail struktur dan konstruksi bangunan tradisional terhadap bangunan galeri seni, terutama pada bagian struktur atap. Struktur atap ditampilkan dengan bentuk dasar atap dengan sudut kemiringan curam pada SBAS dan GL menanggapi curah hujan tinggi di daerah Pulau Jawa. Pada RSC dan PAS, terdapat ekspresi arsitektur lokal Yogyakarta melalui elemen ander dan geganja yang merupakan elemen penahan beban pada struktur bangunan tradisional Jawa. Reinterpretasi mengenai struktur bangunan tradisional muncul pada kolom dan balok RSC, adanya kesan 'ringan' dari kolom yang mampu ditopang oleh material besi sebelum umpak. Pertemuan antara kolom dengan balok juga diselesaikan secara estetis. Pada bangunan PAS, struktur bangunan tradisional pendopo telihat secara eksplisit pada bangunan joglo. Pada kasus VV, bagan fasad terdapat material lokal yang disusun vertikal dengan rangka baja, seperti dinding yang menjadi tabir, tidak sepenuhnya solid.

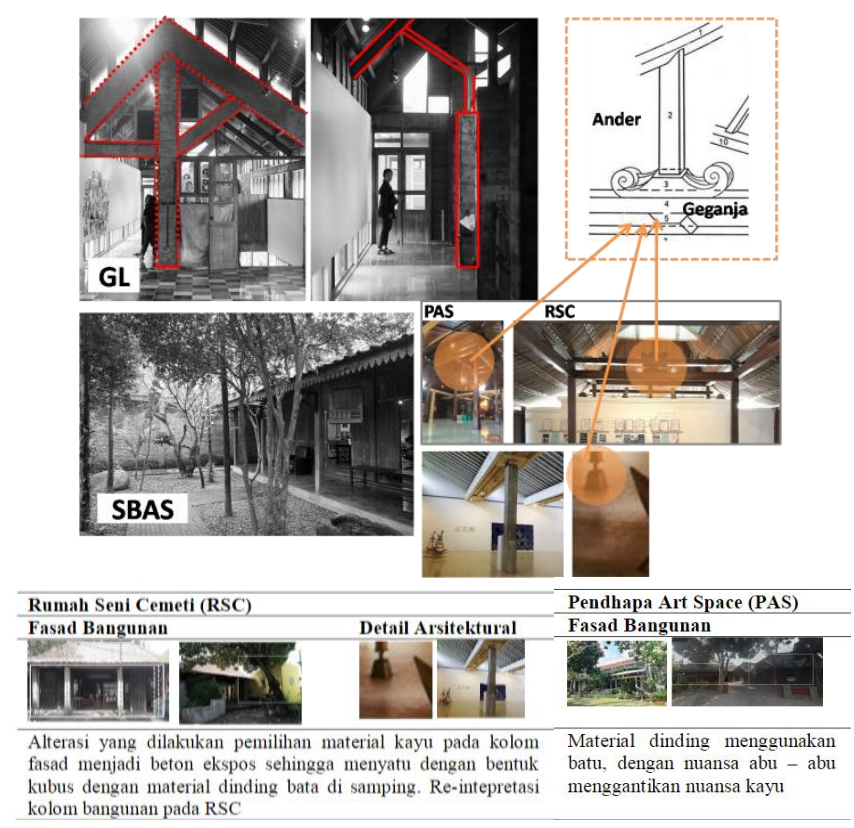

Gambar 7. Reinterpretasi Struktur Dan Konstruksi Yang Estetik Pada Bangunan Galeri Seni Sumber: Olahan Penulis, 2019 


\section{Taktilitas}

Regionalisme kritis mendukung semua material bangunan yang mengaktifkan indra dan yang akan memungkinkan berbagai reaksi emosional manusia. Penggunaan material bertekstur yang dapat dirasakan dengan raga dan peraba manusia dilakukan oleh GL, VV, RSC, dan SBAS. Pada kasus ini terdapat tekstur kasar material bata ekspos, tegel, kaca warna, dan kayu yang diaplikasikan pada dinding (b), lantai (c). Penggunaan tekstur material pada dinding yang paling terlihat di GL, VV, SBAS yang menjadi latar belakang dari karya seni. Pendekatan berbeda dilakukan oleh PAS, KKF, SAS dan LAF. Bangunan tersebut memiliki karakter plafond dan dinding berwarna netral, dalam hal ini adalah warna putih, tidak memiliki tekstur, dan lantai berwarna ivory, kuning gading, maupun tekstur asli dari material mentah (unfinished), yaitu lantai aci semen yang diperhalus. Empat kasus menunjukkan ketiadaan tekstur material yang kasar, melainkan memiliki kesan halus dan bersih. Pada SAS, area display menampilkan material lantai kayu yang bertekstur halus.

Area display galeri masuk ke dalam lingkup interior yang terdiri dari elemen plafond (A), dinding (B), dan lantai (C). Warna dinding yang ditampilkan adalah warna netral (abu-abu muda dan putih) untuk membuat kontras dari karya seni yang ditampilkan, sekaligus untuk menjaga kenetralan area pamer atau area display.

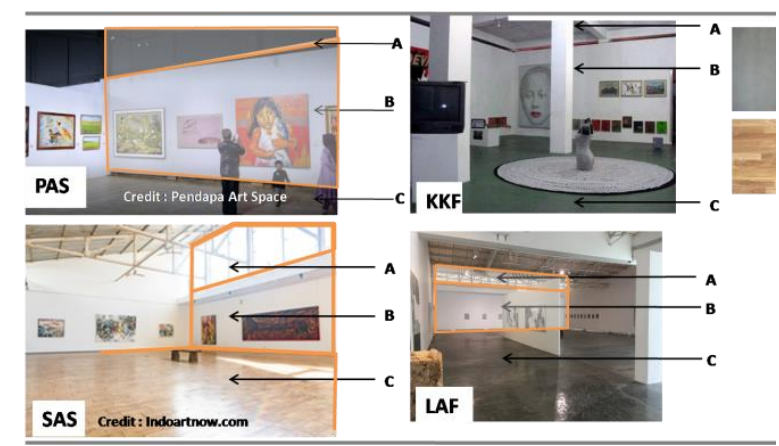

Gambar 8. Galeri Seni Dengan Dominasi Material Moderen

Sumber: Olahan Penulis, 2019

Walaupun tidak kontras dengan karya seni, karya seni tersebut diletakkan pada eye level dan tetap stand out. 'Kontaminasi' dengan material lokal menghadirkan ruang yang tidak 'steril' dan 'higienis' seperti konsep white cube pada referensi pustaka galeri seni.

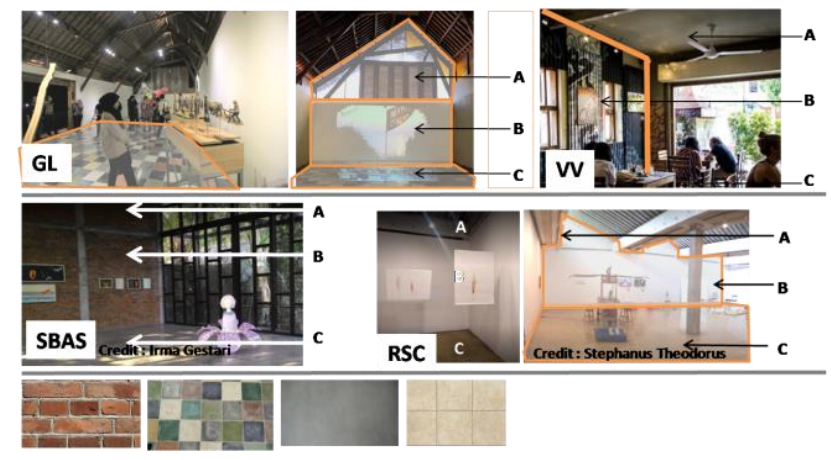

Gambar 9. Galeri Seni Memperlihatkan Kekayaan Tekstur Material Sumber: Olahan Penulis, 2019

Pada kasus GL, terdapat warna-warna pada penggunaan tegel, serta kayu pada fasad galeri seni. Konsep arsitektur Galeri Lorong merupakan konsep 'ugahari' yang dipaparkan oleh Yoshi Fajar yang berakar pada lokalitas, baik dari segi tapak dan penggunaan material. Tekstur material yang 
lebih beragam memberikan nuansa ruang yang lebih hangat dibandingkan galeri seni yang bernampilan steril tanpa tekstur material yang kasar atau lebih teraba.

\section{Iklim: Pencahayaan dan Penghawaan Alami}
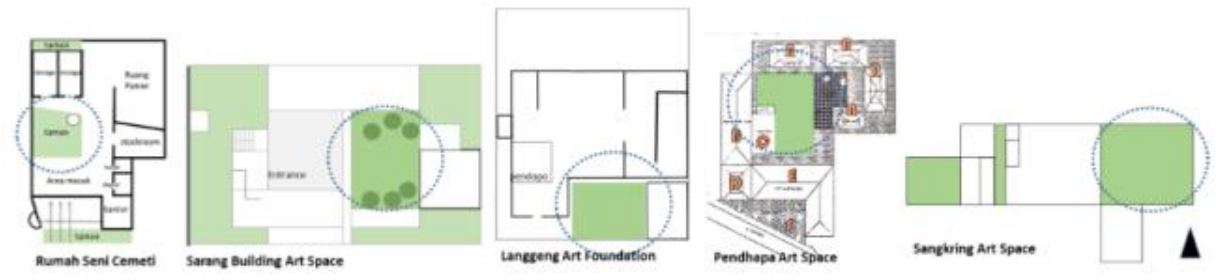

Gambar 10. Tatanan Massa Yang Mengoptimalkan Pencahayaan Dan Penghawaan Alami Sumber: Olahan Penulis, 2019

Bangunan galeri seni merupakan bangunan bermassa plural, dijumpai bukaan berupa innercourt di antara massa satu dengan lainnya. Innercourt berfungsi sebagai pemisah antara zona pameran dengan zona lainnya, misalnya zona seni pertunjukan, kafe, restoran, maupun zona residensi seniman sekaligus sebagai optimalisasi penghawaan alami. Dari kasus yang diobservasi, terlihat bahwa semua kasus bangunan galeri seni melibatkan cahaya alami yang diatur untuk pencahayaan ruang dan pencahayaan karya seni secara tidak langsung. Pencahayaan dari plafon tidak ditemukan dari keempat kasus galeri berikut. Ketiadaan pencahayaan buatan berasal dari plafond menjadi salah satu ciri penting pada konsep white cube gallery karena masing-masing kasus juga memanfaatkan arah matahari untuk pencahayaan alami. Umumnya, pencahayaan alami terletak di bagian atas, sedangkan pencahayaan buatan berada pada drop ceiling. Oleh karena itu, pengunjung tidak merasakan glare atau silau oleh pengaturan tersebut.

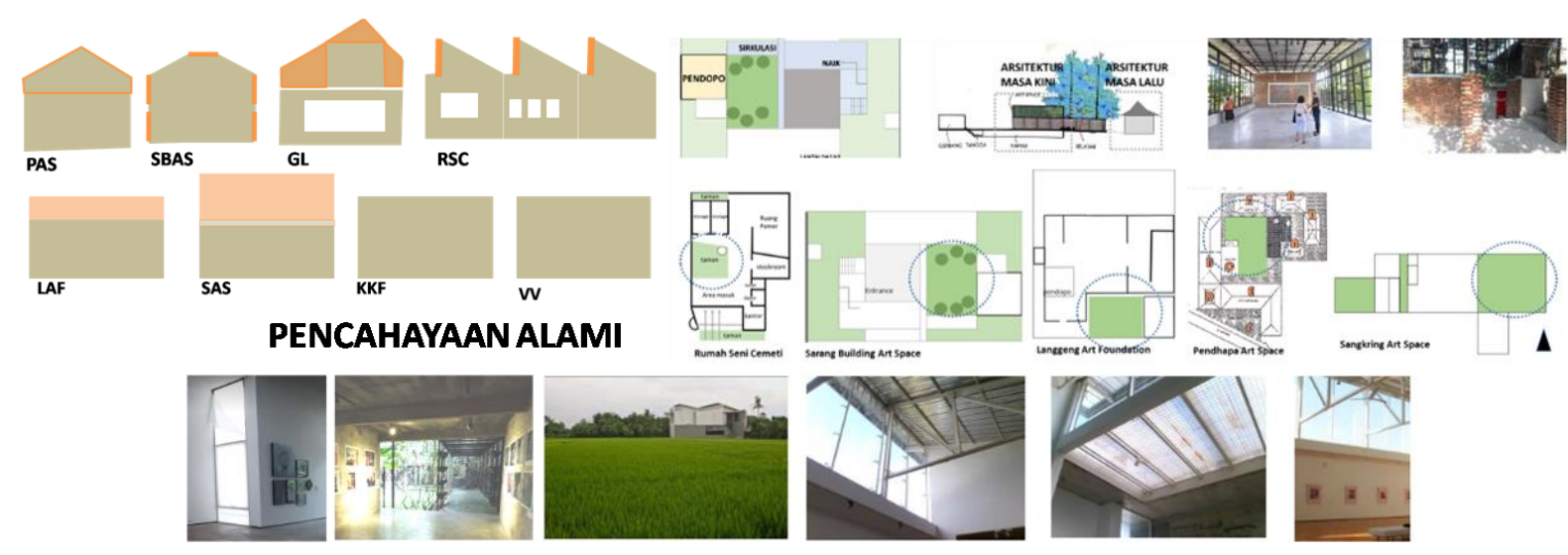

Gambar 11. Pencahayaan Dan Penghawaan Alami Pada Galeri Seni Yang Membuat Ruang Semakin Menarik

Sumber: Berbagai Sumber Diolah Penulis, 2019

Pencahayaan alami dengan bukaan-bukaan di atas secara indirect atau tidak langsung tenyata mempengaruhi bentuk ruang, misalnya pada kasus RSC, bentuk ruang terlihat menarik karena ruang tidak hanya kubistis, dan bukaan mempengaruhi tampilan eksterior. Hal ini berlawanan dengan pendekatan interior white cube yang menyarankan pencahayaan bersifat buatan. Para perancang galeri seni telah mampu mempertimbangkan aspek fisika bangunan sehingga karya seni dapat terjaga. 


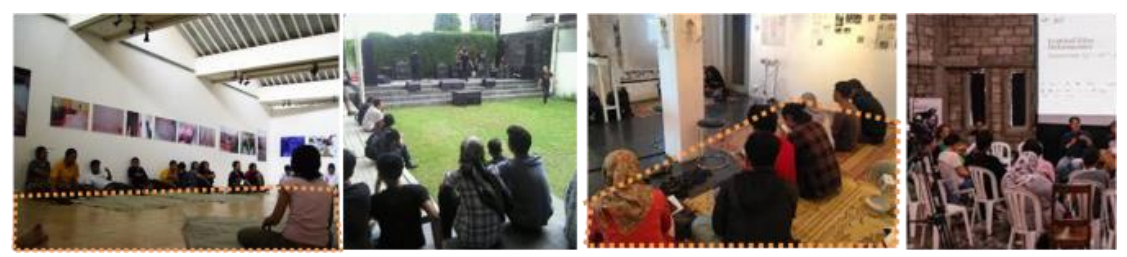

Gambar 12. Suasana Ruang Bernuansa Lokal

Sumber: Berbagai Sumber Diolah Penulis, 2019

Ruang Galeri seni selain untuk berkegiatan pameran seni, kerap digunakan untuk kegiatan lainnya seperti workshop, diskusi publik, penyelenggaraan seni pertunjukan, sampai kuliah umum. Ruang berinteraksi di galeri seni cenderung bersifat informal dan mendukung pengunjung duduk di atas lantai atau lesehan secara berkelompok maupun sendiri tanpa merasa canggung. Hal ini bersinggungan bagaimana pada tataran praksis, praktik arsitektur yang umumnya cenderung formal, teratur, terorganisasi, kemudian mengakomodasi kebiasaan masyarakat setempat dan seniman dalam melakukan kegiatan bersama yang cenderung informal dan 'tidak teratur', terlebih lagi masyarakat lokal dengan kebiasaan lesehan.

\section{Hubungan Bangunan dengan lingkungan Sekitar}

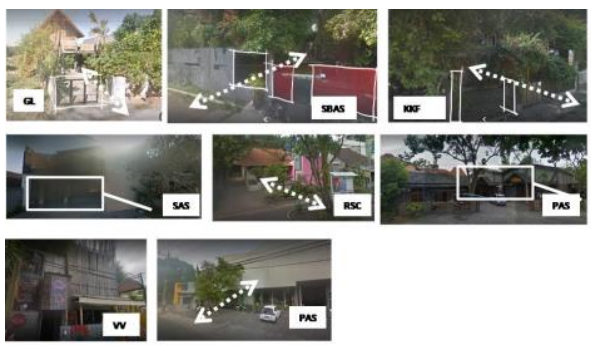

Gambar 13. Hubungan Bangunan Dengan Sekitar Sumber: Olahan Penulis, 2020

Bangunan galeri seni terlihat berusaha menyesuaikan dengan konteks lingkungan sekitar dengan entrance bangunan yang menyesuaikan dengan skala dan proporsi sekitar. Entrance bangunan secara langsung (direct) dari jalan utama pada kasus RSC, LAF, SAS,dan VV. Pada RSC terdapat entrance yang indirect dengan pembatas berupa vegetasi dan tekstur material yang berbeda dari jalan. Transparansi dinding memperlihatkan adanya hubungan antara ruang luar dan ruang dalam sehingga bangunan bukanlah menyerupai kotak-kotak netral.

Setelah proses analisis data dengan komparasi dilakukan, kasus LAF, SAS, dan KKF mendapatkan ketiadaan bentuk yang mencerminkan kedaerahan dan detail-detail strukturkonstruksinya, namun masih terdapat taktilitas, pencahayaan alami, penghawaan alami, ada hubungan dengan sekitar sehingga bangunan bukan merupakan free standing-object. Pendekatan white cube nampak hanya di bagian interior bangunan dan tidak mengganggu eksterior. Pada kasus VV, SBAS, GL nampak bahwa terdapat reinterpretasi bentuk dan tektonika di dalam desain bangunannya. Pencahayaan dan penghawaan alami dihadirkan ke dalam ruang pamer, ruang-ruang transisional melewati innercourt atau rongga di massa bangunan.RSC dan PAS mendekati semua indikator, artinya RSC dan PAS mampu menampilkan lokalitas, namun tidak harus selalu dalam bentuk-bentuk vernakular saja. 
Tabel 1. Analisis Komparasi Antarkasus

\begin{tabular}{|c|c|c|c|c|c|c|c|c|c|}
\hline & $\begin{array}{c}\text { Indikator } \\
\text { Pengamatan }\end{array}$ & LAF & SAS & KKF & SBAS & GL & PAS & RSC & $\mathbf{V V}$ \\
\hline \multirow{3}{*}{ Budaya } & $\begin{array}{l}\text { Bentuk yang } \\
\text { mencerminkan } \\
\text { kedaerahan }\end{array}$ & - & - & - & V & V & V & V & $\mathrm{V}$ \\
\hline & $\begin{array}{l}\text { Tektonik: } \\
\text { reintrepretasi } \\
\text { struktur konstruksi } \\
\text { lokal atau detailnya } \\
\text { yang estetis }\end{array}$ & - & - & - & $\mathrm{V}$ & V & $\mathrm{V}$ & V & $\mathrm{V}$ \\
\hline & Taktilitas : material & $\mathrm{V}$ & $\mathrm{V}$ & $\mathrm{V}$ & $\mathrm{V}$ & $\mathrm{V}$ & $\mathrm{V}$ & $\mathrm{V}$ & $\mathrm{V}$ \\
\hline \multirow{2}{*}{ Iklim } & Pencahayaan Alami & $\mathrm{V}$ & V & $\mathrm{V}$ & V & $\mathrm{V}$ & V & V & $\mathrm{V}$ \\
\hline & Penghawaan Alami & $\mathrm{V}$ & $\mathrm{V}$ & $\mathrm{V}$ & $\mathrm{V}$ & $\mathrm{V}$ & $\mathrm{V}$ & $\mathrm{V}$ & $\mathrm{V}$ \\
\hline \multirow[b]{2}{*}{ Geografi } & $\begin{array}{l}\text { Hubungan dengan } \\
\text { sekitar }\end{array}$ & V & $\mathrm{V}$ & $\mathrm{V}$ & $\mathrm{V}$ & V & $\mathrm{V}$ & $\mathrm{V}$ & $\mathrm{V}$ \\
\hline & $\begin{array}{l}\text { Nuansa ruang yang } \\
\text { mendukung } \\
\text { kedaerahan }\end{array}$ & - & - & $\mathrm{V}$ & $\mathrm{V}$ & V & $\mathrm{V}$ & $\mathrm{V}$ & - \\
\hline
\end{tabular}

Sumber: Penulis, 2020

\section{Kesimpulan}

Bangunan galeri seni di kota Yogyakarta dalam tulisan ini yang paling 'mendekati' white cube pun ternyata tidak mengaplikasikan prinsip-prinsip pendekatannya secara menyeluruh. Semua kasus bangunan galeri seni di Kota Yogyakarta melakukan pendekatan penyelesaian arsitektural berdasarkan iklim setempat. Lebih khususnya 'memperbolehkan' pencahayaan alami untuk ruang pamer di semua kasus. Hal ini mengindikasikan bahwa ruang galeri seni tidak melepaskan diri dari konteks lokasi, yaitu tentang iklim setempat walaupun hal ini dipandang sebagai 'kontaminasi' yang mengganggu karya seni menurut pendekatan white cube. Rupanya, di dalam galeri seni di Yogyakarta, karya seni tidak selalu dibebaskan dari konteks sekitar seperti halnya konsep white cube gallery. Karena galeri seni terutama ruang pamer sudah memiliki konteksnya akibat material, bentuk ruang, ataupun terlihatnya ruang luar, akibatnya para kurator atau penyelenggara kegiatan pameran di galeri harus melakukan pendekatan kuratorial yang berbeda dibandingkan ketika dihadapkan pada galeri dengan pendekatan total white cube. Walapun begitu, kegiatan pameran karya seni saat ini masih semarak di kota Yogyakarta.

Prinsip yang tidak diaplikasikan white cube sekaligus mengindikasikan pendekatan regionalisme kritis dalam bangunan, terlihat dalam taktilitas, yakni adanya keberagaman tekstur material. Tekstur material yang beragam 'teraba' atau 'terasa' menimbulkan sensitivitas sensori manusia yang ditemukan pada semua kasus. Walaupun hal ini bergesekan dengan prinsip white cube gallery di mana ruang harus mampu menyingkirkan distraksi visual. Dalam hal ini, bangunan galeri seni dalam kasus ini disinyalir tetap mampu mencerminkan kedaerahan meskipun sedikit-banyak mengadopsi white cube di bagian interiornya.

\section{Daftar Pustaka}

Bruhn, K. (2013). Art and Youth Culture of the Post Reformasi Era: Social engagement, Alternative expression, and the Public Sphere in Yogyakarta (Ohio University). Retrieved from http://rave.ohiolink.edu/etdc/view?acc_num=ohi ou1364899327

Evon, K. (2017). Thinking Outside the White Cube Polemic Study of Contemporary Art Space (Aalto University). Retrieved from
http://urn.fi/URN:NBN:fi:aalto-201706135249

Frampton, K. (1983). Towards a Critical Regionalism: Six points of an architecture of resistance. In The Anti-aesthetic : essays on postmodern culture.

Hidayatun, M. I., Prijotomo, J., \& Rachmawati, M. (2013). Architectonic pada Arsitektur Nusantara sebagai Cerminan Regionalisme Arsitektur di Indonesia. Prosiding Seminar Jelajah Arsitektur Tradisional Ke V Medan. 
Kimbell Art Museum (2020). Kimbell Art Museum. Retrieved from www.kimbellart.org

Moore, S. (2007). Technology, place, and nonmodern regionalism. Architectural Regionalism: Collected Writings on Place, Identity, Modernity, and Tradition.

O'Doherty, B. (2000). Inside The White Cube. The Ideology of the Gallery Space. Expanded Edition. In University of California Press. Retrieved from http://scholar.google.com/scholar?hl=en\&btnG= Search\&q=intitle:Inside+the+WhiteCube\#5

Rembulan, L. (2014). Penerapan Tektonika Arsitektur YB. Mangunwijaya dalam Perancangan Rumah Tinggal Emha Ainun Nadjib. Arsitektura, 12(1). Retrieved from https://jurnal.uns.ac.id/Arsitektura/article/view/1
$5690 / 12626$

Sari, M. G. (2019). Penerapan Prinsip Regionalisme pada Arsitektur Galeri Seni di Yogyakarta. Jurnal Teknologi Dan Desain, 1(1), 36-44.

Tate Gallery (n.d) Art-terms, White Cube. Retrieved from https://www.tate.org.uk/art/artterms/w/white-cube

White Cube (2020).Exhibitions. Retrieved from https://whitecube.com/exhibitions/exhibition/jeff _wall_masons_yards

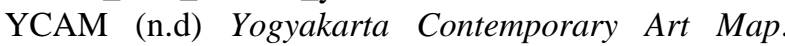
Retrieved from http://artmapjogja.com/ruangseni/ 